\title{
20 Psychodynamics and the Field of Management, Spirituality and Religion: Deciphering the Unconscious, Mapping the Soul
}

\section{Situating Psychodynamic Theories}

The notion of psychodynamics originates with early studies on personality, emotions and cognition. Although the term is most notably associated with Sigmund Freud's psychoanalytical studies as well as the theories of Carl Gustav Jung (Analytical Psychology), Alfred Adler (Individual Psychology) and several of Freud's followers including Melanie Klein and Donald Winnicott (Object Relations approach), its premises lie in the explorations of early psychologists in the late nineteenth and early twentieth century. The work of French psychologist Pierre Janet (1859-1947) notably helped frame the idea of subconscious (or preconscious) and unconscious dynamics influencing personality and behaviour.

Core to this idea is the postulate that the mind is best understood as a complex field of psychic energy (referred to as 'the libido'), whose intensity and quality determines how we process and express the experiences we live. In other words, the mind (or the psyche) is ruled by complex dynamics, many of which occur outside of our conscious awareness, and whose manifestations are very real, be they through the display of emotions, of psychological or somatic disorders, or of patterns of behaviours and personality traits in response to social stimuli.

Of particular interest to psychodynamic psychotherapists are the experiences of conflicts and tensions emerging from this rich, partly unconscious and autonomous inner life of the person. When these conflicts and tensions manifest, they are assumed to be significant and meaningful in the context of the person's unique life, and they are dealt with in a variety of ways ranging from defence mechanisms (from a Freudian lens) to symbolic enactments (from a Jungian lens). The ability to consciously shed light onto the unconscious etiology of our inner turmoil is the main focus of psychodynamic approaches to therapy and to human development. Indeed, by understanding what occurs within ourselves, we start to grasp and address what occurs outside of ourselves, because much of our inner world is arguably projected onto and mirrored through our social world. 


\section{Psychodynamics and MSR: Conceptualizing the Self, the Soul and Patterns of Behaviour in Organizations}

The more notable engagements between the respective fields of psychodynamics and of Management, Spirituality and Religion (MSR) have been around the conceptualization of the (psychological) self in relation to the (spiritual) soul, and the critical analysis of what this means and implies for the study of management and organizations (e.g. Powley \& Cameron, 2006; Roberts, 2007). Doing so has enabled scholars to consider in greater details the normality of emotions and the significance of pathological, unhealthy or harmful behaviours within an organization. It has also paved the way for further ethical reflections on the self-other relationship, touching on notions of meaningfulness and transcendence in a more psychologically-informed manner.

Each psychodynamic tradition comes with its own conceptualization of the self which can help refine, enrich or contrast the views of the self from spiritual traditions, or which can question the outline of the self offered by social science traditions, including management and organizational studies. How we define the self informs how we frame organizational agents, how we interpret the social world, how we make sense of human experiences. It helps us determine whether these experiences are in essence psycho-emotional, socio-political or spiritual, or all at once.

Looking at the past ten years of MSR contributions, we can distinguish three main perspectives that claim a clear anchoring in psychodynamics, namely a Freudian approach, a Jungian approach and, to a lesser extent, a Lacanian approach. Each offers a different perspective on the psyche and on spirituality, outlined below.

\section{Freudian Psychodynamics and MSR}

The Freudian psyche is characterized by an inherent tension between the pleasure principle (rooted in the unconscious, conceptualized as the 'id', leading to fantasies and phantasms) and the reality principle which the conscious ego learns to recognize in order to mediate passions and instincts. The superego emerges through an identification with the lost love-object (the initial parental figure) and leads to the emergence of conscience as a now-internalized moral agency. Our conscious life, then, sees our ego constantly working towards mediating the demands of the id with the censoring power of the superego, all the while negotiating its understanding of 'reality' in order to guide and assess behaviour. 
When it comes to spirituality, Freud was famously reluctant for most of his life to grant much value to religious and spiritual endeavours, referring to it as a "crutch" from which some people find comfort out of the chaos and uncertainty of life, but conceding little evolutionary need for a transcendent experience as such (Walborn, 2014). Although Freud softened his view on the purpose of religion in his final years, his approach to psychodynamics somehow limits the scope of connections with the MSR field. This means that scholars who position themselves within a Freudian view have had to reach beyond the strict structure of a preconscious mind to find ways to explore more collective, humanistic phenomena. This has essentially taken the form of storytelling as a method for studying organizational life.

The most significant contributions in the framing of a dialogue between Freudian psychodynamics and MSR have been made by Gabriel and colleagues. Grounded in an attention to the stories and various narratives that populate work organizations, these writings focus on exposing deep emotions at play (e.g. Fineman \& Gabriel, 1996; Gabriel, 1995, 1997, 1999, 2000, 2004). The study of what emotions are experienced, why they might be experienced then and there, how they are expressed and how they are received, make up a great deal of this scholarship. Over the past decade, we can list the study of disappointment (Clancy et al., 2012) and anger (Lindebaum \& Gabriel, 2016), anxieties around consumption choices (Nixon \& Gabriel, 2016), disgust and 'miasma' (Gabriel, 2012), blame and the need for compassion (Gabriel, 2015), or the fragmentation of our self-identity in the context of unemployment (Gabriel et al., 2013).

These contributions have helped bring nuances to our understanding of organizational life, reinforcing the need to adopt a more historical and holistic view of the self beyond its identity or its role as an organizational agent. The importance of understanding a self in context, of defining a self through its own history and its own stories (be they fantasies or realities), and of recognizing the significance and the normality of seemingly disruptive emotions within a so-called rational organizational system, are major inputs that echo the efforts of MSR scholars to rehabilitate a non-dual, non-simplistic view of human nature. They converge towards an understanding of organizations as complex, at times paradoxical, living systems in which live fragile, yet adaptive and resilient, human beings.

The constant interaction between individuals and systems, shaping one another in constructive or compensatorily destructive ways, therefore becomes a critical dimension of management thinking: in other words, to manage effectively and responsibly, it is essential to account for the various conscious emotional patterns at play, the unconscious (compensatory) motives and needs unveiled, and the capacity of the organization to respond to these conscious and unconscious dynamics. Furthermore, these interactions, even those seemingly disruptive to the smooth running of the organization, are conceived as meaningful, in so far as they reflect people's unconscious desires and aspirations for a collective ideal. Management is 
no longer seen as a science but rather as a delicate craft of deciphering, validating, and even co-constructing meaning and identities.

From this follows a timid interest in rituals and symbolic enactments, both deeply spiritual practices, as integral to organizational life and as necessary for the psycho-emotional well-being of organizational members. This does not quite echo Freud's own view of psychodynamics, because Freud himself did not show much interest in the ongoing need for rituals if one is sufficiently well-adjusted. This stands in contrast with Jung's own view on rituals as symbolic liminal spaces for growth.

\section{Jungian Psychodynamics and MSR}

The Jungian psyche positions the ego as the centre of consciousness whose function is primarily to filter through (or discriminate) the numerous information emerging from the unconscious. The unconscious is partly personal and time-bound (akin to Freud's preconscious state) and, more importantly, partly collective and timeless. This collective unconscious serves as the repository for the entire human experience, recording and carrying forward the instinctive knowledge and intuitive understanding of our ancestors from an archaic time to our present day. For Jung, the collective unconscious, populated by archetypes, shapes a great deal of our lives, including but not limited to, our emotions and our symbolic enactments. Emotions here can be conceived of as cues about our conscious ego's varied attempts to make sense of, compensate for, or relate to the unconscious contents (or archetypal patterns) that present themselves continuously.

The collective unconscious is, in fact, the source of all that we experience consciously, and the reason behind our specific way of making sense of these experiences. Adopting a teleological view, Jung argued that the main drive behind human existence is the ego's conscious reconnection with the archetypal Self, the ultimate symbol of wholeness. From this standpoint, the ego initially emerges out of the collective unconscious (like an original matrix) and develops a growing ability to differentiate from its collective origins, until it realizes the need to return to its collective roots, but this time maintaining a conscious appreciation of that process. This dynamic, to which Jung refers as 'individuation', is not only psychological but also deeply spiritual in so far as it posits the need to transcend the apparent 'consciousness-unconsciousness' duality while recognizing that this tension itself is creative, generative, fruitful, and necessary. This is because without consciousness emerging out of the initial unconscious matrix, there would be no human experiences as such, and therefore no possibility to know what we know. In the collective unconscious, through the experience of the archetypal Self, we can catch a glimpse 
of the Soul of the World (the Anima Mundi), of 'God' in the sense of something transcendent, of whatever unknown potential lies beyond our consciousness.

The Jungian psyche is therefore the most open framework for psychodynamic explorations in the MSR field because it is inherently spiritual as well as psychological. Jung had strong concerns regarding the dogmatic excesses of religion (Jung, 1957/1970), but he recognized that human beings are driven by holistic, spiritual and meaningful needs which pervade a great deal of our interactions and behaviours. Despite this natural fit, works grounded in a Jungian perspective and exploring MSR issues are relatively few. Amongst those, some studies are systematically anchored in a Jungian psychodynamic framework, while others simply borrow some Jungian concepts to enrich their analysis of other organizational literature, but do not embrace the inherently spiritual worldview that a Jungian framework provides. Only those studies that adopt a comprehensive Jungian approach have been reviewed in this section.

Jungian psychodynamics applied to management and organizational studies can be traced back to the 1980s, with notable papers from Denhardt (1981), Mitroff (1983), followed in the 1990s by Bowles (1989, 1990, 1991, 1993a, 1993b, 1997), Jacobson (1993), and Aurelio (1995). These initial contributions each examined, in their own way, the inner dynamics of business organizations and the business world as whole, hinting at the risks of a disconnected, one-sided, soulless business paradigm for the well-being of individuals and groups. By and large, these scholars outlined primarily the significance of myths and the power of archetypes in the design of organizations and the practice of management, and only secondarily did they examine the manifestations of such dynamics amongst organizational members.

They were followed by a few significant articulations of Jungian psychodynamics to organizational life, with Hart and Brady's publication (2005) a notable attempt at including spirituality at the forefront of their analysis. The works of Moxnes (1999, 2013; Moxnes \& Moxnes, 2016) also showcase how Jungian psychodynamics applies to management and leadership studies, although he is much shyer at addressing the spiritual implications of the archetypal dynamics under scrutiny.

In the past decade, a range of contributions have continued to build upon the notion of archetypes to explore the impact of unconscious collective patterns upon the conscious lives of organizations and organizational members (e.g. Kostera, 2012). Aspects of personality types (Lemmergaard \& Howard, 2013), the concept of individuation and development (Brown et al., 2013; Ladkin et al., 2018), the significance of the shadow - our so-called dark side - (Chappell et al., 2019; Ketola, 2012), the persona - our social mask - (Rozuel, 2010), and the archetypal dynamic of the feminine/anima and masculine/animus qualities (e.g. Jironet, 2011, 2019; Rozuel, 2020) have been other modes of engagement with Jungian ideas. In the works cited above, the unconscious is indeed defined as symbolically rich, but the idea that 'Self equates Soul' is rarely acknowledged in clear terms. 
Rozuel (2014a, 2019; Rozuel \& Kakabadse, 2010) is the main author who has explicitly confronted MSR issues from a Jungian psychodynamic perspective. Following Jung in adopting the language of alchemy to decipher the psyche, Rozuel (2014a) notably articulates the nature of wounded soul of organizations and examines the roots and consequences of such a state, before calling for the re-awakening of the Anima Mundi through individual and collective soul-work. The lens of alchemy is further applied to organizational tensions (Rozuel, 2019), this time positioning organizational members as alchemical vessels, and arguing for the re-sacralization of work and the re-enchantment of our worldviews.

On a more interpersonal and intrapersonal level, the Jungian psychodynamics scholarship also contributes to redefining the ethical debate by addressing the ambiguity of unexamined moral aspirations (Kociatkiewicz \& Kostera, 2012; Rozuel, 2011a, 2011b, 2013a, 2016a) and by positioning the imagination as a source of moral insights grounded in the 'Self as Soul' (Rozuel, 2012, 2014b, 2016b)). The source of ethics or of individual moral reflection is no longer restricted to cognitive processes but is presented as a multi-layered psycho-socio-spiritual experience (Rozuel, 2013b, 2016a). The responsibilities of individuals and organizations are more clearly and more honestly articulated, avoiding the recurring trap of blaming the 'bad apples' or the 'bad barrels' alone for wrongdoings, or of sounding too naïve in prescribing moral rules that ignore psychological complexity and ambiguity.

The possibilities of dialogue with religious or spiritual traditions on MSR matters become evident, especially when engaging the imagination to confront and contrast the stories and narratives that infuse both organizational cultures and religious practices. More precisely, this scholarship supports critical reflections on the fact that deep social transformation must be approached creatively from both an individual standpoint (i.e. each person has a responsibility for change) and a collective standpoint (i.e. unconscious patterns influence what each person believes is possible or not). Jungian psychodynamics therefore enable the MSR field to grow out of studies focused on individual experiences of spirituality and religion, as well as out of studies aiming to ground economic principles into spiritual and ethical tenets. It holds that one informs the other, necessarily, and one helps meaningfully transform the other, eventually.

Furthermore, emotions and tensions in organizational life are understood as not only normal but as manifestations of transformative possibilities. These possibilities are approached imaginatively, creatively and inclusively: if Freudian psychodynamics outline a pathway to decipher the unconscious, then Jungian psychodynamics extend this pathway by providing not only a map of possible meanings, but also a toolbox of symbols with which we can creatively go and explore the soul. 


\section{Lacanian Psychoanalysis and MSR}

Another distinct scholarship, derived from the Freudian psychoanalytical tradition, has engaged to some extent with issues pertaining to the MSR field. Building upon the works of Lacan, whose own interpretation of classical psychoanalysis led him to develop an approach emphasizing language and semi-conscious constructions of the self, this scholarship has gained popularity in the field of critical management studies (e.g. Arnaud, 2012; Arnaud \& Vidaillet, 2018). Driver (2005, 2007) has been the main contributor to the conversation between Lacanian psychoanalysis and the MSR field, exploring the ambiguities and contradictions behind organizational spirituality discourses.

The Lacanian psyche is not so much focused on deep dynamics, but rather on the scope and scale of social interactions (be they constructive, repressive, idealized or fantasized) involved in the experience of the self. The self is viewed as being constructed through language and evolving as an imaginary unity that may appear authentic but ends up constraining the full expression of a more fragmented, yet more authentic, ego. The purpose of the ego is, in a Lacanian view, to come to terms with the fact that the image of a unified, stable and all-powerful self is an illusion, and that true subjectivity and creativity is found through the acceptance of an inherently fragmented human nature. This, in turn, paves the way for the emergence of various alternative discourses about the self.

Lacanian psychoanalysis has especially appealed to critical management or organizational scholars because of its central focus on the power play, bridging the socio-political angle with a psychoanalytical angle (e.g. Contu et al., 2010). Indeed, it denounces dominant discourses as potentially oppressive, misappropriated, exploitative or alienating. The authentic spiritual expression of the ego, rather, comes out of that ego stating its struggles with being authentic and with experiencing its spirituality (e.g. Driver, 2010, 2013-2015).

It is worth noting that while the Lacanian perspective does provide a framework for examining social structures around the ego-self, it does not offer a detailed mapping of the inner dynamics of the psyche nor does it leave a space for articulating what a transcendent soul would be like - in fact, those very terms would likely be criticized as alienating and empty. In this regard, the contributions of this scholarship to the MSR field have largely targeted the 'dark side of spirituality' or the deconstruction of a problematic discourse or of an ambiguous identity-making process through the use of short narratives or illustrative vignettes (e.g. Driver, 2009, 2017, 2019; Hudson, 2014). 


\section{Many Crossovers, Few Encounters: The Missed Conversations Between Psychodynamics and MSR}

In reflecting upon the past and the way forward, it becomes clear that there have been many missed conversations between psychodynamic traditions and the MSR field. More precisely, while only three distinct approaches have engaged with MSR topics as outlined above, a great many more have crossed over to management and/or organizational studies for decades. Yet, none of these crossovers have recognized, let alone explored, the spiritual dimension of human needs and human experience in their study of what lies 'below the surface'.

Many more Freudian psychoanalytical approaches to management and leadership than the works cited earlier (e.g. Brunning, 2014; Fotaki et al., 2012; Gabriel \& Carr, 2002; Stein, 2011, 2013, 2015, 2016) have shed light upon the darker side of organizational life, be it the experience of trauma, of scapegoating or of narcissistic inflation. They have demonstrated the need to move beyond the binary view of 'good behaviour' versus 'bad behaviour' in organizations, advocating a more nuanced perspective that recognizes behaviours as shaped through compensatory manifestations of deeper unconscious patterns and that points to the possibility of the constructive development of individuals and organizations if these patterns are indeed recognized as such. Yet, the eventual spiritual drive for such understanding and development is not discussed, and the analysis remains strictly psychoanalytical. In a somewhat similar vein, Kets de Vries's writings on leadership (e.g. Kets de Vries, 2011, 2014, 2019) examine the inner workings of organizational members, some of which deeply unconscious and anchored in compensatory power struggles, but they hardly mention the symbolic or spiritual dimension of leadership - with one notable exception where Kets de Vries (2016) positions leadership coaching as a practice of 'self-retrieval' as akin to the respective shamanic practice and Jungian process of 'soul-retrieval'.

Numerous studies also build upon the Kleinian perspective of Object Relations psychodynamics, sometimes mixed with a classical psychoanalytical grounding (e.g. Petriglieri \& Stein, 2012; Stein, 2019) and spearheaded by the Tavistock Institute in London, England. Yet, they too give little room for explicit considerations of spiritual values or worldviews in their analysis of human relations at work. By and large, these studies focus on framing in a 'psychosocial manner' the emotional and affective experiences of organizational members as mirroring the early relationships with the objects of identification (e.g. Fotaki, 2010; Fotaki \& Hyde, 2015; Kenny \& Fotaki, 2014; see Fotaki et al., 2020 for a rare explicit reference to spirituality).

A further development from this standpoint is the growth of literature on systems psychodynamics (e.g. Gould et al., 2006) which focus on examining the organization as a dynamic psycho-social system whose complexity can be critically grasped through the lens of psychoanalysis. The influence of both Klein's work on early childhood attachment patterns, and Bion's work on groups as well as, to a 
lesser extent, that of positive psychology, is noticeable in the studies anchored in systems psychodynamics, though once again little is said on the spiritual or religious dimension of the human experiences under scrutiny.

Equally rare are scholarly works which have embraced an Adlerian approach to study management and organizational life, irrelevant of any mention of spirituality (see Ambrus, 2013; Nelson, 1999). This is somewhat surprising given how much the Adlerian self is construed as socially oriented, motivated to act by the various expressions of an inferiority complex, and striving for conscious self-expansion through the realization a chosen goal.

\section{Conclusion and Future Directions}

Psychodynamics and MSR remains a niche research area with demonstrated potential for future growth. Psychodynamic approaches ground MSR conversations through their ability to articulate models of the self, of identity, of ego-consciousness, and of unconscious experiences. They help normalize emotions in organizations. They help dig up tensions and make sense of individual and collective behaviours in context. They critically assess the value of spirituality at work. They provide a framework for imagining and constructing inclusive organizations and workspaces which hold us accountable to our ethical values. They bridge inner human experience with transcendent experience.

In this purview, more can be done to position management and leadership practices as legitimately intuitive, emotionally reflexive and contextual, and not merely rational or instrumental. Indeed, if interpersonal relationships are best described as conscious and unconscious energy flows, then there is little relevance for 'one-size-fits-all' models of organizational interventions, management training or leadership development. Instead, more attention is called towards understanding the rich emotional cues on display, the hidden needs behind the words, the symbolic meaning of images and stories that pertain to individuals and to groups. This work necessitates a greater acceptance of intuition and feeling as sources of insights and knowledge on par with 'factual' perceptions and rational analysis. Without it, the surprise element so constitutive of the human experience and of human creativity is lost (Gabriel, 2013).

Another area of desirable collaboration targets the need to re-sacralize and reenchant the world with greater consciousness. Business organizations are typically viewed as the poster child for postmodern disenchantment, yet work is so intrinsically spiritual that we can question how much of that argument is founded (Rozuel, 2019). Psychodynamics have proven useful in the crafting of deeply meaningful rituals, symbols and words that guide and heal people and communities. MSR studies can certainly work more closely with suitable psychodynamic approaches to explore 
how spirit or soul can be reinfused in organizations without this process being naïve, forceful, nor scornful (Rozuel, 2020).

Reflections on work and organizations as sacred spaces lead us further into the moral territory. As we have noted, considering the psychodynamics of the self is inseparable from discussing how these impact others - other selves or other institutions (Rozuel, 2016a). As MSR scholarship attempts to develop more encompassing ways for people to uphold the virtues and values they endorse, psychodynamics can shed light on why moral ambiguity remains, and on what responsibility actually means for individuals and collectives. Building from there, I envision further connections with the workplace well-being agenda and with research on embodiment or psychosomatic experiences at work.

It is however important to underline that not all psychodynamic approaches lend themselves to a fruitful conversation with MSR. More than ever, as we grow our field with the necessary rigour and integrity it deserves, our diligence in ensuring an ontological and epistemological compatibility between the frameworks we use - especially when we mix spiritual worldviews with psychological frameworks is critical. This rigour will further inform the methodologies we use, and the opportunity to ground systematic research in arts-based, creative and participative studies. I argue that the nature of psychodynamics, especially the Jungian perspective, fits Braud's description of "an appropriate tool for exploring topics in more intuitive, holistic, and nonverbal ways” (Braud, 2009, p. 72). The psyche is, just like the soul, a wondrous field of unconscious unknowns and not-yet-knowns, and we can only do it justice if we learn its unique language.

\section{References}

Ambrus, Z. (2013). Public administration in the perspective of Alfred Adler's individual psychology. A discussion. Acta Universitatis Sapientiae. Social Analysis, 3(2), 215-232.

Arnaud, G. (2012). The contribution of psychoanalysis to organization studies and management: An overview. Organization Studies, 33(9), 1121-1135. https://doi.org/10.1177/0170840612448153

Arnaud, G., \& Vidaillet, B. (2018). Clinical and critical: The Lacanian contribution to management and organization studies. Organization, 25(1), 69-97. https://doi.org/10.1177/ 1350508417720021

Aurelio, J. M. (1995). Using jungian archetypes to explore deeper levels of organizational culture: Facing your organization's psyche. Journal of Management Inquiry, 4(4), 347-368. https:// doi.org/10.1177/105649269500400407

Bowles, M. L. (1989). Myth, meaning and work organization. Organization Studies, 10(3), 405-421. https://doi.org/10.1177/017084068901000306

Bowles, M. L. (1990). Recognizing deep structures in organizations. Organization Studies, 11(3), 395-412. https://doi.org/10.1177/017084069001100304

Bowles, M. L. (1991). The organization shadow. Organization Studies, 12(3), 387-404. https://doi. org/10.1177/017084069101200303 
Bowles, M. L. (1993a). The gods and goddesses: Personifying social life in the age of organization. Organization Studies, 14(3), 395-418. https://doi.org/10.1177/017084069301400304

Bowles, M. L. (1993b). Logos and eros: The vital syzygy for understanding human relations and organizational action. Human Relations, 46(11), 1271-1290. https://doi.org/10.1177/ 001872679304601101

Bowles, M. L. (1997). The myth of management: Direction an dfailure in contemporary organizations. Human Relations, 50(7), 779-803. https://doi.org/10.1023/A: 1016912507723

Braud, W. (2009). Dragons, spheres, and flashlights: Appropriate research approaches for studying workplace spirituality. Journal of Management, Spirituality \& Religion, 6(1), 59-75. https://doi.org/10.1080/14766080802648557

Brown, M. L., McDonald, S., \& Smith, F. (2013). Jungian archetypes and dreams of social enterprise. Journal of Organizational Change Management, 26(4), 670-688. https://doi.org/10.1108/ JOCM-Sep-2012-0146

Brunning, H. (2014). Psychoanalytic Essays on Power and Vulnerability. Routledge.

Chappell, S., Cooper, E., \& Trippe, G. (2019). Shadow work for leadership development. Journal of Management Development, 38(5), 326-335. https://doi.org/10.1108/JMD-08-2018-0216

Clancy, A., Vince, R., \& Gabriel, Y. (2012). That unwanted feeling: A psychodynamic study of disappointment in organizations: that unwanted feeling. British Journal of Management, 23(4), 518-531. https://doi.org/10.1111/j.1467-8551.2011.00780.x

Contu, A., Driver, M., \& Jones, C. (2010). Editorial: Jacques Lacan with organization studies. Organization, 17(3), 307-315. https://doi.org/10.1177/1350508410364095

Denhardt, R. (1981). Is the Shadow of Organization. University Press of Kansas.

Driver, M. (2005). From empty speech to full speech? Reconceptualizing spirituality in organizations based on a psychoanalytically-grounded understanding of the self. Human Relations, 58(9), 1091-1110. https://doi.org/10.1177/0018726705059038

Driver, M. (2007). A "spiritual turn" in organizational studies: Meaning making or meaningless? Journal of Management, Spirituality \& Religion, 4(1), 56-86. https://doi.org/10.1080/ 14766080709518646

Driver, M. (2009). Struggling with lack: A lacanian perspective on organizational identity. Organization Studies, 30(1), 55-72. https://doi.org/10.1177/0170840608100516

Driver, M. (2010). Learning as lack: Individual learning in organizations as an empowering encounter with failed imaginary constructions of the self. Management Learning, 41(5), 561-574. https://doi.org/10.1177/1350507610374427

Driver, M. (2013). The lack of power or the power of lack in leadership as a discursively constructed identity. Organization Studies, 34(3), 407-422. https://doi.org/10.1177/0170840612463003

Driver, M. (2014). The stressed subject: Lack, empowerment and liberation. Organization, 21(1), 90-105. https://doi.org/10.1177/1350508412464897

Driver, M. (2015). How trust functions in the context of identity work. Human Relations, 68(6), 899-923. https://doi.org/10.1177/0018726714548080

Driver, M. (2017). Never social and entrepreneurial enough? Exploring the identity work of social entrepreneurs from a psychoanalytic perspective. Organization, 24(6), 715-736. https://doi. org/10.1177/1350508416665474

Driver, M. (2019). Who will I be when I retire? Introducing a Lacanian typology at the intersection of present identity work and future narratives of the retired self. Human Relations, 72(2), 322-343. https://doi.org/10.1177/0018726718761553

Fineman, S., \& Gabriel, Y. (1996). Experiencing Organizations. Sage.

Fotaki, M. (2010). Why do public policies fail so often? Exploring health policy-making as an imaginary and symbolic construction. Organization, 17(6), 703-720. https://doi.org/10.1177/ 1350508410366321 
Fotaki, M., Altman, Y., \& Koning, J. (2020). Spirituality, symbolism and storytelling in twentyfirstcentury organizations: Understanding and addressing the crisis of imagination. Organization Studies, 41(1), 7-30. https://doi.org/10.1177/0170840619875782

Fotaki, M., \& Hyde, P. (2015). Organizational blind spots: Splitting, blame and idealization in the National Health Service. Human Relations, 68(3), 441-462. https://doi.org/10.1177/ 0018726714530012

Fotaki, M., Long, S., \& Schwartz, H. S. (2012). What can psychoanalysis offer organization studies today? Taking stock of current developments and thinking about future directions. Organization Studies, 33(9), 1105-1120. https://doi.org/10.1177/0170840612448152

Gabriel, Y. (1995). The unmanaged organization: Stories, fantasies and subjectivity. Organization Studies, 16(3), 477-501. https://doi.org/10.1177/017084069501600305

Gabriel, Y. (1997). Meeting God: When organizational members come face to face with the supreme leader. Human Relations, 50(4), 315-342. https://doi.org/10.1023/A: 1016938410023

Gabriel, Y. (1999). Organizations in Depth. SAGE Publications.

Gabriel, Y. (2000). Storytelling in Organizations: Facts, Fictions, and Fantasies: Facts, Fictions, and Fantasies. Oxford Univeristy Press.

Gabriel, Y. (2004). Myths, Stories, and Organizations: Premodern Narratives For Our Times. Oxford University Press.

Gabriel, Y. (2012). Organizations in a state of darkness: Towards a theory of organizational miasma. Organization Studies, 33(9), 1137-1152. https://doi.org/10.1177/0170840612448154

Gabriel, Y. (2013). Surprises: Not just the spice of life but the source of knowledge.M@ N@ Gement, 16(5), 719-731.

Gabriel, Y. (2015). Beyond compassion: Replacing a blame culture with proper emotional support and management comment on "why and how is compassion necessary to provide good quality healthcare?" International Journal of Health Policy and Management, 4(9), 617-619. https:// doi.org/10.15171/ijhpm.2015.111

Gabriel, Y., \& Carr, A. (2002). Organizations, management and psychoanalysis: An overview. Journal of Managerial Psychology, 17(5), 348-365. https://doi.org/10.1108/ 02683940210432600

Gabriel, Y., Gray, D. E., \& Goregaokar, H. (2013). Job loss and its aftermath among managers and professionals: Wounded, fragmented and flexible. Work, Employment and Society, 27(1), 56-72. https://doi.org/10.1177/0950017012460326

Gould, L. J., Stapley, L. F., \& Goregaokar, H. (2006). The Systems Psychodynamics of Organizations: Integrating the Group Relations Approach, Psychoanalytic, and Open Systems Perspectives. Routledge.

Hart, D. W., \& Brady, F. N. (2005). Spirituality and archetype in organizational life. Business Ethics Quarterly, 15(3), 409-428.

Hudson, R. (2014). The question of theoretical foundations for the spirituality at work movement. Journal of Management, Spirituality \& Religion, 11(1), 27-44. https://doi.org/10.1080/ 14766086.2013.801031

Jacobson, K. H. (1993). Organization and the Mother archetype: A Jungian analysis of adult development and self-identity within the organization. Administration and Society, 25(1), 60-84. https://doi.org/10.1177/009539979302500104

Jironet, K. (2011). Female Leadership: Management, Jungian Psychology, Spirituality and the Global Journey Through Purgatory. Routledge.

Jironet, K. (2019). Feminine Leadership: Personal Development Beyond Polarities (2nd ed.). Routledge.

Jung, C. G. (1957). The undiscovered self. In C. G. Jung (Ed.), Civilization in Transition (2nd ed., Vol. 10). Princeton University Press. 
Kenny, K., \& Fotaki, M. (2014). The Psychosocial and Organization Studies: Affect at Work. Palgrave Macmillan. https://books.google.at/books?id=zQ5HBQAAQBAJ

Ketola, T. (2012). Losing your self: Managerial persona and shadow pressures killing responsible leadership. Journal of Management Development, 31(5), 470-487. https://doi.org/10.1108/ 02621711211226051

Kets de Vries, M. F. R. (2011). Reflections on Groups and Organizations. John Whiley \& Sons.

Kets de Vries, M. F. R. (2014). Mindful Leadership Coaching: Journeys Into the Interior. Palgrave Macmillan.

Kets de Vries, M. F. R. (2016). The shaman, the therapist, and the coach. Organisational and Social Dynamics, 16(1), 1-18.

Kets de Vries, M. F. R. (2019). Down the Rabbit Hole of Leadership: Leadership Pathology in Everyday Life. Palgrave Macmillan.

Kociatkiewicz, J., \& Kostera, M. (2012). The good manager: An archetypical quest for morally sustainable leadership. Organization Studies, 33(7), 861-878. https://doi.org/10.1177/ 0170840612445124

Kostera, M. (2012). Organizations and Archetypes. Edward Elgar Publishing.

Ladkin, D., Spiller, C., \& Craze, G. (2018). The journey of individuation: A jungian alternative to the theory and practice of leading authentically. Leadership, 14(4), 415-434. https://doi.org/ $10.1177 / 1742715016681942$

Lemmergaard, J., \& Howard, C. (2013). Do it my way: A study on type, leadership and emotions. In J. Lemmergaard \& S. Muhr, Critical Perspectives on Leadership (pp. 59-85). Edward Elgar Publishing. https://doi.org/10.4337/9780857931139.00011

Lindebaum, D., \& Gabriel, Y. (2016). Anger and organization studies: From social disorder to moral order. Organization Studies, 37(7), 903-918. https://doi.org/10.1177/0170840616640848

Mitroff, I. I. (1983). Archetypal social systems analysis: On the deeper structure of human systems. Academy of Management Review, 8(3), 387-397. https://doi.org/10.5465/amr.1983.4284373

Moxnes, P. (1999). Deep roles: Twelve primordial roles of mind and organization. Human Relations, 52(11), 1427-1444. https://doi.org/10.1177/001872679905201104

Moxnes, P. (2013). The Hero's dream and other primordial patterns of imagery: Archetypal influences on organisational fantasies and ideations. Journal of Organizational Change Management, 26(4), 638-653. https://doi.org/10.1108/JOCM-02-2013-0023

Moxnes, P., \& Moxnes, A. (2016). Are we sucked into fairy tale roles? Role archetypes in imagination and organization. Organization Studies, 37(10), 1519-1539. https://doi.org/ $10.1177 / 0170840616634135$

Nelson, M. D. (1999). Applying individual psychology to the study of organizational dynamics. Individual Psychology, 55(2), 200-208.

Nixon, E., \& Gabriel, Y. (2016). 'So much choice and no choice at all': A socio-psychoanalytic interpretation of consumerism as a source of pollution. Marketing Theory, 16(1), 39-56. https://doi.org/10.1177/1470593115593624

Petriglieri, G., \& Stein, M. (2012). The unwanted self: Projective identification in leaders' identity work. Organization Studies, 33(9), 1217-1235. https://doi.org/10.1177/0170840612448158

Powley, E. H., \& Cameron, K. S. (2006). Organizational healing: Lived virtuousness amidst organizational crisis. Journal of Management, Spirituality \& Religion, 3(1-2), 13-33.

Roberts, C. (2007). Executives' fractured spirit and dissociation at work. Journal of Management, Spirituality \& Religion, 4(2), 160-186. https://doi.org/10.1080/14766080709518656

Rozuel, C. (2010). Moral tension in the psyche: A Jungian interpretation of managers' moral experiences. EJBO Electronic Journal of Business Ethics and Organization Studies, 15(1), 36. 
Rozuel, C. (2012). Moral imagination and active imagination: Searching in the depths of the psyche. Journal of Management Development, 31(5), 488-501. https://doi.org/10.1108/ 02621711211226060

Rozuel, C. (2019). Unearthing gold from the mud: Alchemy and organizational tensions. Journal of Management, Spirituality \& Religion, 16(2), 178-198. https://doi.org/10.1080/ 14766086.2018.1524785

Rozuel, C. (2020). Rushing fools and wise women: Tales for organisations aiming to improve lives. In M. Schwartz \& H. Harris (Eds.), Research in Ethical Issues in Organizations (pp. 101-122). Emerald Publishing Limited. https://doi.org/10.1108/S1529-209620200000023006

Rozuel, C. (2014a). Calling to the Anima Mundi: On restoring soul within organizations. Journal of Management, Spirituality \& Religion, 11(2), 123-142. https://doi.org/10.1080/ 14766086.2013.801320

Rozuel, C. (2016b). Challenging the 'million zeros': The importance of imagination for business ethics education. Journal of Business Ethics, 138(1), 39-51. https://doi.org/10.1007/s10551015-2639-8

Rozuel, C. (2013a). Daimon and psyche: Ethical reflections on a numinous marriage. International Journal of Jungian Studies, 5(3), 211-225. https://doi.org/10.1080/19409052.2013.795182

Rozuel, C. (2013b). Exemplarity as commitment to the self: Insights from spiritual healers. Research in Ethical Issues in Organizations, 10, 117-151. https://doi.org/10.1108/S1529-2096 (2013)0000010010

Rozuel, C. (2016a). Jung's insights on ethics in business and work organisations: Examining the 'moral nature of present-day man.' International Journal of Jungian Studies, 8(3), 141-158. https://doi.org/10.1080/19409052.2016.1200110

Rozuel, C. (2014b). Otherness in self and organisations: Kafka's "the metamorphosis" to stir moral reflection. In M. Schwartz \& H. Harris (Eds.), Research in Ethical Issues in Organizations (Vol. 11, pp. 25-50). Emerald Group Publishing Limited. https://doi.org/10.1108/S1529. 209620140000011002

Rozuel, C. (2011a). The moral threat of compartmentalization: Self, roles and responsibility. Journal of Business Ethics, 102(4), 685-697. https://doi.org/10.1007/s10551-011-0839-4

Rozuel, C. (2011b). Transcending business ethics: Insights from Jung and Maslow. EJBO Electronic Journal of Business Ethics and Organization Studies, 16(1), 41-47.

Rozuel, C., \& Kakabadse, N. (2010). Ethics, spirituality and self: Managerial perspective and leadership implications. Business Ethics: A European Review, 19(4), 423-436. https://doi.org/ 10.1111/j.1467-8608.2010.01603.x

Stein, M. (2011). A culture of mania: A psychoanalytic view of the incubation of the 2008 credit crisis. Organization, 18(2), 173-186. https://doi.org/10.1177/1350508410390071

Stein, M. (2013). When does narcissistic leadership become problematic? Dick Fuld at Lehman Brothers. Journal of Management Inquiry, 22(3), 282-293. https://doi.org/10.1177/ 1056492613478664

Stein, M. (2015). Double trouble: Sibling rivalry and twin organizations in the 2008 credit crisis: Double trouble. British Journal of Management, 26(2), 182-196. https://doi.org/10.1111/14678551.12072

Stein, M. (2016). 'Fantasy of fusion' as a response to trauma: European leaders and the origins of the eurozone crisis. Organization Studies, 37(7), 919-937. https://doi.org/10.1177/ 0170840615622070

Stein, M. (2019). The lost good self: Why the whistleblower is hated and stigmatized. Organization Studies, 017084061988056. https://doi.org/10.1177/0170840619880565

Walborn, F. (2014). Religion in Personality Theory. Academic Press. 